\title{
How Often and Under Which Circumstances Do Mexican Pharmacy Vendors Recommend Misoprostol To Induce an Abortion?
}

\begin{abstract}
CONTEXT: Misoprostol was used by women across Mexico to induce abortion even before 2007, when first-trimester abortion was legalized in Mexico City. Pharmacy vendors' misoprostol recommendation practices across subregions of Mexico after abortion legalization warrant examination.
\end{abstract}

METHODS: Overall, 192 pharmacies in four regions of Mexico were randomly selected and visited by simulated clients presenting three scenarios (a young woman, an adult woman and a male partner). Bivariate and multivariate analyses were used to explore associations between pharmacy, vendor and client characteristics and drug access.

RESULTS: In 558 encounters with simulated clients, $78 \%$ of vendors provided information about misoprostol-18\% recommended it spontaneously and $60 \%$ recommended it only after the client asked specifically for the drug. Fifteen percent of vendors recommended a potentially effective misoprostol dosing regimen. Mexico City-based pharmacies and those in the Central region were significantly less likely than those in the North region to require a prescription to sell misoprostol (odds ratios, 0.2 and 0.3 , respectively). Independent pharmacies and those from low-income areas were significantly more likely to sell misoprostol by the pill than chain pharmacies and those in medium-income areas (3.2 and 2.7, respectively).

CONCLUSIONS: Access to misoprostol is influenced by neighborhood socioeconomic level, pharmacy location and pharmacy type. The frequently inaccurate and incomplete information provided to clients about using misoprostol for abortion suggests the need to improve pharmacy vendor training in medication abortion options and to develop ways to directly inform women about misoprostol use.

International Perspectives on Sexual and Reproductive Health, 2011,37(2)75-83, doi: 10.1363/3707511
By Diana Lara, Sandra G. García, Kate S. Wilson and Francisco Paz

Diana Lara is project manager, Ibis Reproductive Health, Oakland, CA, USA. Sandra G. García is senior associate and country director, Population Council, Mexico City.

Kate S. Wilson is an independent consultant, Mexico City. Francisco Paz is researcher, Instituto

Nacional de

Neurología y

Neurocirugía, Mexico City.
Misoprostol is a prostaglandin analogue originally licensed for the treatment of gastric ulcers; it is also important for the treatment of gynecologic and obstetric conditions because it stimulates uterine activity. ${ }^{1}$ Misoprostol forms part of the medication abortion regimen recommended by the World Health Organization (WHO), which consists of the administration of mifepristone followed by misoprostol. ${ }^{2}$ In countries in which mifepristone is not available, misoprostol can be used alone to induce abortions, with an effectiveness of $84-96 \%{ }^{3}$ When misoprostol is used alone, WHO recommends a dosage of 800 mcg administered vaginally every 24 hours for up to three doses, until 63 days of gestation. ${ }^{2}$

Since 1985, misoprostol has been sold in Mexican pharmacies under the commercial name Cytotec, but the prices and prescription requirement to purchase it vary. ${ }^{4}$ Cytotec belongs to drug group IV (including antibiotics, steroids, antihypertensive and antiseizure drugs); regulations require that medications in this group be sold by prescription only. In practice, however, such drugs are often sold without a prescription. ${ }^{5}$ Because of the sensitivity of the topic and the legal implications of self-induced abortions in Mexico, where abortion is mostly illegal outside of the capital, it is difficult to investigate pharmacy vendors' knowledge about misoprostol's abortifacient properties and the information they provide to clients who request it.

Simulated clients have been widely used in pharmacybased studies; 6 the methodology has advantages over interviews because it reduces observation bias. ${ }^{7}$ Posing as clients and presenting a particular scenario, trained fieldworkers engage providers to seek information in a situation similar to what the provider might be expected to encounter on any given day of routine service. Providers are unaware that these clients are involved in research.

According to three studies using simulated clients conducted in Latin American countries, pharmacy vendors are aware of the abortifacient properties of misoprostol, but have limited knowledge about effective doses and do not provide sufficient counseling or follow-up instructions. ${ }^{8-10}$ A study conducted in Mexico City in 2003 reported that pharmacy vendors recommended misoprostol in 39\% of the scenarios in which a simulated client asked for a drug to "induce menstruation," but that in only 17\% of those interactions did pharmacy workers actually provide correct information about an effective dosage. ${ }^{8}$ In a 2006 study conducted in one Mexican state, $90 \%$ of pharmacy vendors discussed misoprostol either spontaneously or after being prompted by a simulated client, but the majority of these vendors did not provide accurate information about dosage, mode of administration or what women should 
expect during the abortion process. ${ }^{10}$

The aim of this study was to learn more about the recommendation of misoprostol in pharmacies in eight Mexican cities; these cities included Mexico City, where elective first-trimester abortion was legalized in April 2007. ${ }^{11}$ This study began six months after the legalization in Mexico City, which triggered a heated debate about abortion throughout the country. We hypothesized that in areas of the country with restrictive abortion laws, Cytotec information and sales would be limited. Therefore, we explored how willing the pharmacy vendors were to provide information about and sell Cytotec in cities in the North, Central and South/East regions of the country, and systematically documented the quality of the information being provided.* In addition, we examined how frequently vendors recommended other drugs that combine misoprostol with diclofenac (a nonsteroidal anti-inflammatory drug [NSAID]), which have similar abortifacient properties, but are much less expensive than misoprostol. We further hypothesized that some vendors would be aware of the abortifacient properties of these drugs and would recommend them as alternatives to misoprostol alone.

\section{METHODS Selection of Pharmacies}

We used a national database of Mexican pharmacies from a governmental department (Sistema de Información Empresarial Mexicano) that contains information about businesses and services at the country level. At the time of this study in 2007, the database had information on 2,994 pharmacies- $77 \%$ independent and $22 \%$ chain pharmacies. Chain pharmacies are members of a branded pharmacy with a central distributor and have more staff, while independent pharmacies have fewer staff, and frequently the owners or owners' relatives work as vendors.

We selected the eight cities included in the study because they represent different socioeconomic levels and geographic regions as defined by the National Population Council. ${ }^{12}$ The four regions are Mexico City (the country's

*In this article, we identified cities by region rather than by name to protect the confidentiality of the pharmacy and vendors and to avoid possible negative repercussions (e.g., imposition of legal restrictions on Cytotec sales in pharmacies).

†States in each region: North: Aguascalientes, Baja California, Baja California Sur, Chihuahua, Coahuila, Colima, Jalisco, Mexico, Nuevo León, Sonora and Tamaulipas; Central: Campeche, Durango, Guanajuato, Michoacán, Morelos, Nayarit, Puebla, Querétaro, Quintana Roo, San Luis Potosí, Sinaloa, Tabasco, Tlaxcala, Yucatán and Zacatecas; South/East: Chiapas, Guerrero, Hidalgo, Oaxaca and Veracruz; and Mexico City (Federal District).

¥Middle socioeconomic status: Neighborhoods with completed houses or medium-sized apartments on surfaces of 150-300 square meters. The majority of residences have one-car garages. Generally, they have very small yards or none. This includes subsidized housing units. The areas are paved and have sidewalks. Public transportation runs frequently. Low socioeconomic status: Public housing developments with small apartments. The maintenance in the buildings and in the housing complex is irregular. Not all areas are paved or have sidewalks. If there are any green spaces, they are poorly maintained.

§In the original Spanish phrasing of the scenario we used the term "interrumpir el embarazo," which literally means "to interrupt a pregnancy." This more culturally accepted, less stigmatized term is commonly used by Mexicans to refer to abortion. most developed and populous city), the North (more developed), the Central (less developed) and the South/East (least developed). ${ }^{\dagger}$ We selected a convenience sample consisting of Mexico City, the capital cities of two states in the North region, the capitals of two states in the Central region and the capitals of three states in the South/East region.

In each of the eight cities, we selected a random sample of 12 independent pharmacies and 12 chain pharmacies. In each of these groups, we classified the pharmacies by their location in low socioeconomic status areas and middle socioeconomic status areas using the official geographic maps developed by the Mexican government (Areas Geoestadísticas Básicas). We repeated the randomized selection process until we had a quota of six pharmacies located in middle socioeconomic status areas and six pharmacies located in low socioeconomic status areas. ${ }^{\ddagger}$ We did not include pharmacies located in middlehigh and high socioeconomic status areas because we hypothesized that Cytotec sales in those areas would be lower than in middle and low socioeconomic status areas because women in these areas typically have more access to clinical abortion services and more economic resources.

Some pharmacies that we originally selected did not have correct contact information or had relocated; therefore, we replaced them with 39 pharmacies of the same type in similar locations. The substitutions prevented us from maintaining randomization at the individual pharmacy level, although we were able to do so at the levels of socioeconomic status and pharmacy type; we accounted for the substitutions in the analysis. We estimated a sample size of 24 pharmacies, or 72 pharmacy-client encounters, per city. This sample size gave us $90 \%$ confidence of detecting the true number of staff who were familiar with Cytotec within 10 percentage points, assuming that $40 \%$ would be familiar with the drug and that the no-response rate would be $10 \%$. We chose a proportion of $40 \%$ on the basis of a previous study conducted in Mexico City, in which $39 \%$ of the vendors recommended Cytotec. ${ }^{8}$

\section{Methodology}

We sent three types of simulated clients to each of the selected pharmacies: a young woman (aged 18-25), an adult woman (aged 26-35) and an adult man (aged 20-30) who claimed that his girlfriend was pregnant. We decided to use different client scenarios because we expected that adult women and men would obtain more and better quality information about Cytotec than young women, since societies tend to view youth as sexually promiscuous and irresponsible about pregnancy prevention. ${ }^{13}$

The female simulated clients were trained to provide the following scenario: "My menstrual period is two weeks late. My last period was six weeks ago. I had a positive pregnancy test. Could you please tell me what drug I could take to interrupt a pregnancy?"§ If the vendor did not mention Cytotec spontaneously, the client would ask directly about Cytotec, explaining that a friend had recommended the drug and asking if he or she knew if it was available at 
the pharmacy and if it worked. When the simulated client was a man, he modified the wording to say that his girlfriend was pregnant and that he was requesting the drug for her. We trained four women and two men in each city to act out the scenarios. From September to December 2007 , each of the three types of simulated clients visited each of the 24 pharmacies in the eight cities.

We decided that clients would approach the pharmacy vendor and ask directly for an abortion-inducing drug instead of asking for a drug to regulate menstruation because recent qualitative research ${ }^{10}$ suggests that women mention Cytotec more frequently when inquiring about drugs to interrupt a pregnancy than when asking about drugs to regulate menstruation.

In all scenarios, the simulated client approached the first available pharmacy worker and described his or her situation. If the vendor spontaneously mentioned more than one drug, the clients were instructed to ask, "Which drug is the most important, the one I should be sure to take?" (¿Cuál es la más importante, la que no me debo dejar de tomar?) If the vendor mentioned any drug containing misoprostol alone, misoprostol in combination with diclofenac, or methotrexate, but did not spontaneously offer information on usage, the simulated clients were instructed to ask detailed questions about these drugs, including dosage, route of administration, effectiveness, side effects, complications, where to go in case of complications, availability of the drug in the pharmacy, how the drug is sold and cost. Simulated clients were trained to provide standardized responses to potential questions by pharmacy staff and to conclude the interaction by saying that he or she did not have enough money on hand to purchase the drug, but would return later to do so. Each simulated client was accompanied by someone of the same sex who was trained to pose as a friend. The job of this companion was to quietly observe the interaction, but not interact directly with anyone. We added the companion for methodological purposes-to help ensure that the simulated client's perceptions of the interaction were objective and to help improve information recall.

Following each visit, the mystery client and the companion completed a detailed data collection form describing the client-vendor interaction. The form included information the vendor mentioned spontaneously about the drugs, the drug the vendor recommended most highly, the information provided spontaneously about misoprostol and misoprostol in combination with other drugs, as well as any information that the vendor provided after the client asked directly for Cytotec about dosage, route of administration, effectiveness, side effects, complications, where to go in case of complications, availability of the drug at the pharmacy, how the drug is sold and cost. Because they did not ask vendors for any personal information, in the interest of keeping the scenario as realistic as possible, clients also recorded their perceptions about the vendor's age and position (i.e., distinguishing between a vendor with some authority-such as a supervisor-versus a regular vendor). This study was approved by the Population Council's institutional review board.

\section{Measures}

Because we were not certain about the process that women follow when they ask for abortifacient drugs in pharmacies, we hypothesized that one of two potential situations might occur, and we modeled the mystery client situations on the basis of these assumptions. In the first scenario, the client asked for any drug to induce an abortion and waited for the vendor's spontaneous recommendation. In the second scenario, the client specifically asked for Cytotec, telling the pharmacy vendor that a friend had recommended the drug and asking if he or she knew if it was available at the pharmacy and if it worked. We created two outcome variables based on these situations: Recommendation of Cytotec when the client asked for something to induce an abortion, and provision of information after the client specifically requested Cytotec.

We were also interested in exploring the following three variables that could influence women's access to Cytotec. The first variable was recommendation of an effective dosage of Cytotec, defined as any client-vendor interaction in which the vendor recommended an effective dose (three or more pills per day or 600 mcg per day, over any number of days, and using any route of administration-oral, buccal or vaginal) either spontaneously or after the client requested information on Cytotec. The second was requirement of a prescription to sell Cytotec. Finally, the third variable was availability of the drug by individual pill in the pharmacy, used as an indicator of the drug's availability for abortifacient purposes rather than to treat gastric ulcers. For example, because each bottle of Cytotec normally contains 28 pills (200 mcg in each pill), enough to induce three (eight pills each) to nine (three pills each) abortions, we hypothesized that the individual sale of pills indicated their sale for inducing abortions. We defined this third variable as any client-vendor interaction in which the vendor stated that Cytotec was available in pills or mentioned cost per pill either spontaneously or after the client request.

\section{Analysis}

We used SPSS 14.0 and Stata 10.0 to conduct the data analyses. We conducted chi-square and Student's t tests to evaluate differences in the proportions and means. We performed a bivariate analysis to explore associations between the six outcome variables mentioned above and the following independent variables: Type of client who interacted with the vendor (a young woman, an adult woman or a man); gender of the pharmacy staff; and pharmacy characteristics, including region in which the pharmacy was located (North, Central, South/East or Mexico City), socioeconomic level of pharmacy neighborhood (middle or low) and type of pharmacy (independent or chain). We performed logistic regression analyses to explore the associations between these independent variables and two outcome variables: requirement of a prescription to sell the drug and availability of the 
TABLE 1. Percentage distribution of pharmacy vendors, by responses to simulated clients who asked for a drug to interrupt a pregnancy, Mexico, 2007

Response

Spontaneously recommended a drug to interrupt

a pregnancy

Yes

No

Drugs spontaneously recommended by vendorst

Misoprostol only (sold as Cytotec)

Combination of misoprostol with diclofenac $\neq$

Methotrexate

Hormonal injectables

Oxytocin

Emergency contraception

Other§

Recommended an abortifacient drug or

a combination of such drugs

Yes

No

Drugs and combination of drugs spontaneously recommended by vendors

Only misoprostol

Only drugs combining misoprostol and diclofenac

Combination of abortifacient drugs

with nonabortifacient drugs

Combination of nonabortifacient drugs

The preferred drugt†

Cytotec

Combination of misoprostol with diclofenac

Hormonal injectables

Oxytocin

Emergency contraception

Otherf‡

Total

$\%$

$(\mathrm{N}=558)$

23.7

76.3

$(\mathrm{N}=176)$

56.2

11.4

2.3

12.5

3.4

13.1

1.1

$(\mathrm{N}=132)$

81.8

18.2

$(\mathrm{N}=132)$

49.2

10.6

22.0

18.2

$(\mathrm{N}=132)$

73.5

7.6

6.1

0.7

11.4

0.7

100.0

tSome of the vendors recommended more than one drug; 176 drugs were recommended by 132 pharmacy vendors. ‡Artren, Artrotec and Artrenac §Includes an unspecified contraceptive method and an unspecified natural product. + lf vendors recommended more than one drug, the simulated clients were instructed to ask which was the preferred drug. $\neq \neq$ An unspecified natural product.

drug by individual pill at the pharmacy. In all models, we controlled for pharmacy characteristics, type of client and gender of pharmacy worker. Associations were considered statistically significant at $\mathrm{p}<.05$. The association between pharmacy characteristics and recommendation of effective doses could not be tested because the sample size was too small (only 89 vendors provided information about dosage); we report this in the bivariate analysis only. We also conducted a qualitative analysis with information gathered from 13 of the 14 vendors who spontaneously recommended any drug containing misoprostol and diclofenac, and who provided information on usage and costs.

\section{RESULTS}

\section{Characteristics of Pharmacies and Pharmacy Staff}

In 18 of the 576 client-vendor interactions (3\%), the vendor did not provide any information to the client and did not answer any of the questions that the mystery clients asked; thus our analysis includes data from 558 clientvendor interactions. According to the information provid- ed by the simulated clients, $63 \%$ of the pharmacy staff approached were women, and 55\% appeared to be younger than 30 years old; $73 \%$ were vendors, $16 \%$ were managers and $11 \%$ were owners (not shown).

\section{Recommendation of Abortifacient Drugs}

Twenty-four percent of the pharmacy vendors spontaneously recommended a drug to induce abortion (Table 1 ). The most important reasons vendors cited for not spontaneously mentioning a drug were that they did not know about any (33\%; not shown) or that they did not sell abortifacient drugs (28\%). Some vendors suggested that the client go to a general practitioner or an obstetriciangynecologist (17\%), and some said they only dispensed drugs and did not see patients (11\%). A few vendors recommended that the client go to a public hospital to get an abortion (5\%), stated that abortion was legal in Mexico City (4\%), said that the pharmacy was prohibited from selling abortifacients ( $1 \%$ ) or said that they were too busy $(1 \%)$.

One hundred and thirty-two vendors spontaneously recommended a total of 176 drugs to the simulated clients. More than half of these vendors (54\%; not shown) mentioned more than one drug; some mentioned drugs with abortifacient properties, such as drugs that contain misoprostol and methotrexate (82\%), and others mentioned drugs without such properties, such as hormonal injectables, oxytocin or emergency contraception (18\%). Almost half of all vendors who made spontaneous recommendations recommended taking Cytotec only, 11\% recommended taking any of the three brands of drugs that contain misoprostol and diclofenac, 22\% mentioned a combination of an abortifacient with a nonabortifacient drug and 18\% recommended only nonabortifacient drugs. When the client asked the vendor which drug of the ones recommended was the most effective in inducing abortion, 74\% cited Cytotec, followed by emergency contraception ( $11 \%$ ), products containing a combination of misoprostol and diclofenac (8\%), hormonal injections (6\%), oxytocin (1\%) and unspecified "natural" products (1\%).

\section{Recommendation of Cytotec}

Overall, in $78 \%$ of the client-vendor interactions, the vendor provided some information about Cytotec (not shown). Cytotec was spontaneously recommended in $18 \%$ of the 558 encounters with simulated clients; in $60 \%$, the vendor confirmed knowing about Cytotec when the client asked for it directly, including 4\% in which the vendor also spontaneously recommended another drug to induce an abortion and $56 \%$ in which the vendor did not mention any other drug spontaneously. In 20\% of the client-vendor interactions, the vendor did not know about Cytotec when the client asked about it and did not spontaneously recommend any other drug to induce an abortion.

Spontaneous recommendation of Cytotec was significantly more common in pharmacies located in low socioeconomic status areas than in those located in medium so- 
cioeconomic status areas (54\% vs. 47\%; Table 2). In contrast, in the interactions in which the client asked directly for the drug, the proportion of vendors who provided information about Cytotec was significantly higher among those in chain pharmacies than among those in independent pharmacies ( $56 \%$ vs. $45 \%$ ). Also, the proportion of vendors providing Cytotec information after the client's request varied significantly by region; it was highest in cities located in the Central (34\%) and South/East (33\%) regions. There were no differences in provision of Cytotec information related to the type of client or gender of the pharmacy worker.

\section{Completeness and Accuracy of Cytotec Information}

In the majority of the vendor-client interactions, vendors provided incomplete information about dosage, route of administration, side effects, complications and where to go in case of complications (Table 3, page 80). Some of the vendors provided information about dosage, but not about the number of doses per day or number of days required for treatment. Eighty vendors provided information about dosage and number of doses per day and 87 gave information about the number of days of treatment (not shown). When the simulated client asked about the number of doses per day, 22 vendors responded by saying "[Do] whatever your physician prescribed."

Fifteen percent of all the vendors who provided information about Cytotec (spontaneously or after request) recommended an effective dose of $600 \mathrm{mcg}$ per day. Only 3\% of the vendors who provided information about Cytotec recommended a safe and effective regimen of $600 \mathrm{mcg}$ per day for 1-3 days. A bivariate analysis to identify differences in the recommendation of effective doses between vendors who made a spontaneous recommendation of Cytotec and those who made a recommendation after the client requested Cytotec found no statistically significant differences (not shown). The route of administration mentioned most often was oral only (39\%), followed by a combination of oral and vaginal (9\%) and vaginal only (3\%); $49 \%$ of the vendors did not provide any information about route of administration.

Almost half of the vendors alerted clients to the possibility of at least one side effect. The side effects most frequently mentioned were bleeding (35\%), cramps (25\%) and nausea (10\%). Almost half of the vendors offered information about one or more potential complications from the use of misoprostol; 39\% mentioned hemorrhage, $8 \%$ mentioned fetal malformations and 3\% mentioned that the implantation of the fetus would become even stronger ("Se va a pegar más fuerte"). Almost half of the vendors mentioned at least one place to go in case of complications either spontaneously or when the client asked. Thirty-six percent mentioned the emergency room, 13\% a clinic and $3 \%$ a specific clinic or doctor.

Cytotec was stocked in 63\% of the pharmacies. Overall, $45 \%$ of pharmacies sold it by the bottle and $9 \%$ by the pill, while $47 \%$ provided no information about how it was sold.

\begin{tabular}{|c|c|c|}
\hline Characteristic & $\begin{array}{l}\text { Spontaneous } \\
\% \\
(\mathrm{~N}=99)\end{array}$ & $\begin{array}{l}\text { After client's request } \\
\% \\
(\mathrm{~N}=335)\end{array}$ \\
\hline \multicolumn{3}{|l|}{ Client type } \\
\hline Young woman & 28.3 & 36.7 \\
\hline Adult woman & 36.4 & 31.6 \\
\hline Adult man & 35.4 & 31.6 \\
\hline \multicolumn{3}{|l|}{ Pharmacy type } \\
\hline Independent & 52.5 & $44.5^{* *}$ \\
\hline Chain & 47.5 & 55.5 \\
\hline \multicolumn{3}{|c|}{ Socioeconomic level } \\
\hline Low & $53.5^{* *}$ & 47.8 \\
\hline Medium & 46.5 & 52.2 \\
\hline \multicolumn{3}{|l|}{ Region } \\
\hline North & 27.3 & $22.4 * * *$ \\
\hline Central & 9.1 & 33.7 \\
\hline South/East & 48.5 & 32.8 \\
\hline Mexico City & 15.2 & 11.0 \\
\hline \multicolumn{3}{|c|}{ Gender of pharmacy worker } \\
\hline Female & 58.6 & 62.1 \\
\hline Male & 41.4 & 37.9 \\
\hline Total & 100.0 & 100.0 \\
\hline
\end{tabular}

In $35 \%$ of the client-vendor interactions, the vendor said a prescription was required. In a bivariate analysis, we compared the provision of Cytotec usage information against no provision of information by the type of interaction that the client had with the vendor (i.e., either spontaneous recommendation of Cytotec or after request). For all variables, we found that vendors who spontaneously recommended Cytotec also frequently provided more information than vendors who said they knew about Cytotec only after the client requested it. All differences were statistically significant at $\mathrm{p}<0.01$ (not shown).

\section{Requirement of Prescription and Sale by Individual Pill}

In logistic regression models that controlled for gender of the pharmacy vendor, pharmacy characteristics (type of pharmacy, neighborhood socioeconomic level and region) and client scenario (young woman, adult woman and male), we found that pharmacies in the Central region and Mexico City had significantly lower odds of requiring a prescription for Cytotec than did those located in the North region (odds ratios, 0.3 and 0.2 , respectively; Table 4 , page 81 ). In the model that explored the characteristics associated with sale of Cytotec by individual pill, the odds of selling the drug by pill were three times as high for independent pharmacies as for chain pharmacies (3.2), and nearly three times as high for pharmacies located in low socioeconomic status areas as for those in middle socioeconomic status areas (2.7). Compared with pharmacies in the North region, those in the South/East or Mexico City had greater odds of selling Cytotec by pill ( 7.6 and 11.0, respectively). Finally, with respect to recommenda- 
TABLE 3. Percentage of pharmacy vendors who provided misoprostol-related responses to simulated clients'requests for an abortifacient, either spontaneously or after clients asked specifically for the drug

Response $\%$

\section{Dosage}

Effective ( $\geq 3$ pills/day)

Not effective (1-2 pills/day)

No information provided

\section{$\%$} $(\mathrm{N}=434)$

Length of treatment

$1-3$ days

4-28 days

"Until you finish the bottle"

"Until the period comes"

No information provided

5.5

79.5

A safe and effective regiment

Yes

No

No information provided

Route of administration

Only oral

Only vaginal

Oral and vaginal

Buccal

No information provided

\section{Side effects $¥$}

Diarrhea

Cramps

Nausea

Vomiting

Bleeding

No information provided

\section{Complications‡}

Hemorrhage

Fetal malformations

"The implantation would be stronger"

Other§

No information provided

Where to go in case of complications;

Emergency room

Clinic

Clinic or doctor with contact information

No information provided

\section{Available at the pharmacy}

No

No information provided

\section{Sold by the pill at the pharmacy}

Yes

No

No information provided

\section{Prescription required}

Yes

No

No information provided

\section{Costt†}

Bottle

Individual pill tion of an effective dosage (bivariate analysis only; not shown), we found that vendors in the North recommended effective dosages less frequently (20\%) than those in the other regions (Central, 25\%; South/East, 34\%; and Mexico City, 22\%), and female vendors recommended effective dosages more frequently than male vendors (54\% vs. $46 \%$ ).

\section{Information About Other Drugs Containing Misoprostol}

Fourteen vendors recommended only drugs that contained a combination of misoprostol and diclofenac, and 13 of them provided further information to the client about how to use the drugs (not shown). Not all of the 13 vendors, however, provided complete information. Seven vendors recommended Artrotec, five recommended Artene and one recommended Artrenac. ${ }^{*}$ Four vendors gave information on dosages, the number of doses and the number of days the client needed to take the drug, and three of them recommended an effective dosage of at least $600 \mathrm{mcg}$ of misoprostol. Eleven vendors recommended oral administration, one recommended vaginal administration and one recommended injectable administration. All of the vendors verified that the drug was stocked and available in the pharmacy, and five of them told the client a prescription was required to buy the drug. Only two of 13 vendors provided the client with information about how the drug is sold and recommended a bottle of 30 pills of Artrotec, but did not provide information about the cost. Six vendors said they sold the drug by individual pill, but none of them provided any cost information. The most frequently cited side effects were cramps, followed by bleeding, nausea and vomiting. The most frequently mentioned potential complications were hemorrhage, fetal malformation, fetal death with no expulsion and uterine surgery. Twelve vendors advised the women where to go in case of complications and some mentioned more than one place; six mentioned the emergency room, six gave contact information of a specific clinic and two mentioned a clinic without providing contact information.

\section{DISCUSSION}

This study illustrates that provision of information about Cytotec by pharmacy vendors in Mexico is common. Cytotec was the drug most frequently mentioned spontaneously by pharmacy vendors when mystery clients requested a drug to induce an abortion. Unlike other studies in Mexico, 8,10,14 in which the drugs most frequently recommended as abortifacients were actually hormonal injections, a low proportion of the vendors in our study mentioned such injections. In our study, the second mostrecommended drug was emergency contraception, which

†A safe and effective regimen is at least $600 \mathrm{mcg}$ per day over a 1-3 day period. $\neq$ The total in the percentages do not sum to $100 \%$ because some vendors mentioned more than one side effect, complication or place to go in the case of complications. §Other complications mentioned were infection; uterine problems, such as perforation; need for surgery; infertility and possible death. †+Mean (and standard deviation) shown in US\$. Original information was collected in Mexican pesos. Exchange rate was 10.5 pesos per US\$1.00 as of March

28,2008. Note: Unless otherwise noted, figures are percentages.
*Artrotec, Artrenac and Artrene vary in the number of pills per bottle (10-30 pills) and the amount of misoprostol (50-200 mcg) and diclofenac (50-150 mg) per pill. Artrotec contains the highest dosage of misoprostol $(200 \mathrm{mcg})$ and the lowest dosage of diclofenac $(50 \mathrm{mg})$, and therefore could be considered the safest and most effective of the abortifacient pills containing diclofenac and misoprostol. 
was recommended even when the simulated clients said explicitly that they had already received a positive pregnancy test. Confusion about the differences between emergency contraception and medication abortion has been reported anecdotally as well as in peer-reviewed articles on Mexico. ${ }^{15}$ Higher spontaneous recommendation of Cytotec than of other drugs might result in part from vendors' greater awareness of the abortifacient properties of Cytotec or from the clients having asked pharmacy vendors explicitly for a drug to induce abortion instead of a drug to induce or regulate menstruation. Conversely, clients' explicit requests for an abortifacient may explain why spontaneous recommendations of any abortifacient drug was lower in our study (24\%) than in prior studies conducted in Mexico in which more than half of the vendors spontaneously made a recommendation when asked for a drug to induce menstruation. ${ }^{8,10}$

In our study overall, the vendors provided some information about Cytotec in $78 \%$ of the client-vendor interactions-18\% spontaneously and 60\% after having been prompted by the client. A study conducted in a Mexican state in 2006 reported similar frequency and patterns of provision of Cytotec information in which a total of $90 \%$ of vendors discussed misoprostol-19\% spontaneously and $71 \%$ after being prompted by the client. ${ }^{10}$ A 2003 study conducted in Mexico City reported higher levels of spontaneous recommendation of Cytotec (39\%). ${ }^{8}$

Despite the fact that most pharmacy vendors knew about Cytotec, few provided any dosage information, and when they did it was usually a dosage that would be ineffective at inducing an abortion. This lack of detailed knowledge is consistent with findings reported in other studies in this population. 8,10 Lower recommendation of Cytotec dosages may be related to a fear of the legal consequences of recommending abortifacients in a country in which abortion is legally restricted outside the capital. It seems that recommending Cytotec without providing dosage information but also advising women where to go in case of complications may have been the safest way for pharmacy vendors to avoid legal consequences while helping women who wanted an abortion.

The provision of information about misoprostol varied according to several factors. Vendors were more likely to recommend Cytotec spontaneously when they worked in pharmacies located in areas of low socioeconomic status rather than in those in areas of medium socioeconomic status, while they were more likely to provide information only after a client requested it in chain pharmacies and pharmacies located in cities in the Central and South/East regions than in independent pharmacies and those in other regions. It is likely that in smaller cities, where pharmacies might have a larger proportion of regular clients, it is more difficult to maintain complete anonymity; this in turn might explain why those vendors chose to give information only if the client asked directly about Cytotec. In addition, our observation that recommending the drug after the clients specifically requested it is more frequent

\begin{tabular}{|c|c|c|}
\hline Characteristic & $\begin{array}{l}\text { Required } \\
\text { prescription } \\
(\mathrm{N}=386)\end{array}$ & $\begin{array}{l}\text { Sold drug } \\
\text { by the pill } \\
(\mathrm{N}=231)\end{array}$ \\
\hline \multicolumn{3}{|l|}{ Client type } \\
\hline Young woman (ref) & 1.00 & 1.00 \\
\hline Adult woman & $0.67(0.39-1.15)$ & $1.47(0.55-3.78)$ \\
\hline Adult man & $1.21(0.72-2.03)$ & $1.70(0.67-4.32)$ \\
\hline \multicolumn{3}{|l|}{ Pharmacy type } \\
\hline Independent & $0.97(0.63-1.50)$ & $3.17(1.46-6.91)$ \\
\hline Chain (ref) & 1.00 & 1.00 \\
\hline \multicolumn{3}{|l|}{ Socioeconomic level } \\
\hline Low & $0.75(0.49-1.16)$ & $2.66(1.20-5.87)$ \\
\hline Medium (ref) & 1.00 & 1.00 \\
\hline \multicolumn{3}{|l|}{ Region } \\
\hline North (ref) & 1.00 & 1.00 \\
\hline Central & $0.33(0.18-0.62)$ & $4.01(0.90-17.76)$ \\
\hline South/East & $0.79(0.46-1.34)$ & $7.55(2.01-28.37)$ \\
\hline Mexico City & $0.20(0.09-0.46)$ & $10.96(2.68-44.83)$ \\
\hline \multicolumn{3}{|l|}{ Vendor's gender } \\
\hline Female & $1.16(0.74-1.80)$ & $1.27(0.58-2.78)$ \\
\hline Male (ref) & 1.00 & 1.00 \\
\hline
\end{tabular}

Note: ref=reference group.

in chain pharmacies than in independent ones might be explained by greater staff supervision found in chain pharmacies and potentially negative consequences for a staff member who spontaneously recommended an abortifacient. Contrary to what we expected, spontaneous and prompted provision of information about Cytotec was similar across the three scenarios presented by the simulated clients. This suggests that young women may not in fact face greater difficulties or stigma than adult women or men in obtaining Cytotec through pharmacies.

Even though Cytotec was available in the majority of the pharmacies that the mystery clients visited, there were nevertheless some situations in which clients had difficulty obtaining misoprostol because of the requirement for a prescription, the vendor's lack of information about effective dosages and the lack of drug availability by individual pill. Clients in the North region, for example, had more limited access to misoprostol than clients in the other regions because vendors in the North required a prescription more often, sold Cytotec by individual pill less frequently and recommended effective doses less frequently. By contrast, pharmacies in Mexico City and cities in the Central region had the fewest prescription requirements. In our study, vendors were more likely to require a prescription than vendors in previous studies in Mexico. ${ }^{8,10}$ This could be explained by the widespread availability of public information on Cytotec's abortifacient properties, or perhaps by the fact that the liberalization of the Mexico City abortion laws was being hotly debated in the media at the time of our study.

Furthermore, the sale of Cytotec by individual pill occurred more often in our study than it did in previous 
studies. ${ }^{8,10}$ Our findings suggest that sales by individual pill were, in fact, quite common in pharmacies located in areas of low socioeconomic status and in independent pharmacies. This situation would benefit women who cannot afford to purchase a bottle of Cytotec or obtain a surgical abortion. We must interpret this finding with caution, however, because there are anecdotal reports of sales of individual Cytotec pills at very high prices as well as sales of fake drugs packaged as Cytotec. In addition, researchers have reported that retail pharmacies located in low-income neighborhoods and in rural areas more frequently provide incorrect drug recommendations, have poor dispensing practices and sell products at higher prices than pharmacies in other areas. ${ }^{16,17}$ Given the barriers women might face in obtaining correct misoprostol instruction through pharmacy vendors, research on the best ways to educate women about safe and effective misoprostol use is warranted.

In our study, drugs containing misoprostol in combination with diclofenac were third on the list of drugs spontaneously recommended by the vendors. In addition, the majority of vendors recommended the brand that contains the highest dose of misoprostol and therefore could be the most effective abortifacient. This is the first study that reports vendors' recommendation of these drugs. These drugs can effectively induce an abortion and are considerably less expensive than Cytotec. For example, a package of Artrotec (30 pills) costs approximately US $\$ 20$, compared with Cytotec (28 pills) which costs US\$140. Although some studies have shown that NSAIDs do not interfere with the effectiveness of mifepristone and misoprostol regimens in inducing second-trimester abortions, ${ }^{18}$ further investigation is needed to evaluate drug effectiveness in the first trimester and to learn more about the recommendation of these drugs as abortifacients, especially in settings in which Cytotec may not be available or where women cannot afford it.

This study has several limitations. The major limitation of the use of simulated clients was that these clients may not have been able to obtain sufficient in-depth information about misoprostol because the data they gathered depended on the willingness of the vendor to provide the information; they were not able to ask for further information or clarification as one could in a face-to-face interview without risking discovery. Also, because the simulated clients spoke with the first pharmacy vendor they encountered in each pharmacy, it is possible that that vendor's views differed from others on staff. It is possible that the pharmacy staff suspected that the simulated clients were not real clients; however, we feel this possibility was diminished by the rigorous training the simulated clients received in preparation for their roles. We must also consider that some women in need of an abortifacient may have visited a friend or acquaintance who worked in a pharmacy instead of requesting information from an unknown vendor. In addition, the sale of any drug by individual pill does not appear to be consistent across sites, but may instead be more frequent in independent pharmacies and in those located in lowincome areas. This variation may have affected the results in our multivariate model. Finally, the simulated clients' reports may have suffered from recall bias because they recorded observations from memory following the interaction; again, however, we feel that recall bias was minimized by the presence of the companion, whose sole function was to observe the interaction.

This study fills an important information gap on misoprostol-related pharmacy interactions and highlights the need for pharmacy vendor trainings on Cytotec and other misoprostol-based abortifacients (in Mexico City and states in which abortion is legal under certain circumstances), emergency contraception and other reproductive health topics. It also emphasizes the need to explore other channels through which to provide accurate instructions directly to women about the safe and effective use of misoprostol to induce an abortion, especially in situations in which pharmacy vendors are unwilling to provide instructions. To avoid backlash by conservative policymakers and the potential withdrawal of the drug from the market, as occurred in Brazil in the 1990s, the provision of information about misoprostol through pharmacies and the training of pharmacy vendors must be conducted with caution in Mexico (at least in areas outside Mexico City) and in other countries in which abortion remains legally restricted. ${ }^{19}$ Nevertheless, in light of the liberalization of the abortion law in Mexico City, the launch of elective abortion services in public hospitals in April 2007 and the high demand for these services by Mexican women even in legally restrictive states, it is necessary to improve the provision of accurate information about correct use of misoprostol.

\section{REFERENCES}

1. Bracken H, Providing Medical Abortion in Developing Countries: An Introductory Guidebook, second ed., New York: Gynuity Health Projects, 2009

2. von Hertzen H et al., Efficacy of two intervals and two routes of administration of misoprostol for termination of early pregnancy: a randomized controlled equivalence trial, Lancet, 2007, 369(9577):19381946.

3. Moreno-Ruiz NL et al., Alternatives to mifepristone for early medical abortion, International Journal of Gynaecology \& Obstetrics, 2007, 96(3):212-218

4. Sherris J et al., Misoprostol use in developing countries: results from a multicountry study, International Journal of Gynaecology $\&$ Obstetrics, 2005, 88(1):76-81.

5. Mexico City, Cámara de Diputados del H. Congreso de la Unión, art. 226, June 2, 2004

6. Huntington D and Schuler SR, The simulated client method: evaluating client-provider interactions in family planning clinics, Studies in Family Planning, 1993, 24(3):187-193

7. Madden JM et al., Undercover careseekers: simulated clients in the study of health provider behavior in developing countries, Social Science \& Medicine, 1997, 45(10):1465-1482.

8. Lara D et al., Pharmacy provision of medical abortifacients in a Latin American city, Contraception, 2006, 74(5):394-399.

9. Miller S et al., Misoprostol and declining abortion-related morbidity in Santo Domingo, Dominican Republic: a temporal association, BJOG, 2005, 112(9):1291-1296. 
10. Billlings DL et al., Pharmacy worker practices related to use of misoprostol for abortion in one Mexican state, Contraception, 2009, 79(6):445-451.

11. Distrito Federal, Decreto por el que se reforma el Código Penal para el Distrito Federal y se adiciona la Ley de Salud para el Distrito Federal, 2007, art. 1, Órgano de Gobierno del Distrito Federal, No. 70, April 26, 2007.

12. Consejo Nacional de Población (CONAPO), Índices de Marginación, 2000, Mexico City: CONAPO, 2000.

13. Juarez F et al., Addressing Adolescent Women's Sexual and Reproductive Health Needs in Mexico: Challenges and Opportunities, New York: Guttmacher Institute, 2010, <http://www.guttmacher.org/ pubs/Adolescentes-Mexico.pdf>, accessed Feb. 23, 2011 (in Spanish).

14. Pick S et al., Pharmacists and market herb vendors: abortifacient providers in Mexico City, in: Mundigo AI and Indriso C, eds., Abortion in the Developing World, London: Zed Books, 1999, pp. 293-310.

15. Gould H, Ellertson C and Corona G, Knowledge and attitudes about the differences between emergency contraception and medical abortion among middle-class women and men of reproductive age in Mexico City, Contraception, 2002, 66(6):417-426.

16. Alte D, Weitschies W and Ritter CA, Evaluation of consultation in community pharmacies with mystery shoppers, Annals of Pharmacotherapy, 2007, 41(6):1023-1030.

17. Goel PK et al., Influence of location and staff knowledge on quality of retail pharmacy prescribing for childhood diarrhea in Kenya, International Journal for Quality in Health Care, 1996, 8(6):519-526.

18. Fiala $C$ et al., The effect of non-steroidal anti-inflammatory drugs on medical abortion with mifepristone and misoprostol at 13-22 weeks gestation, Human Reproduction, 2005, 20(11):3072-3077.

19. Costa SH, Commercial availability of misoprostol and induced abortion in Brazil, International Journal of Gynaecology $\&$ Obstetrics, 1998, 63(Suppl. 1):S131-S139.

\section{RESUMEN}

Contexto: Aún antes de 2007, cuando se aprobó en la Ciudad de México la Interrupción Legal del Embarazo (ILE) del primer trimestre, las mujeres de todo México usaron el medicamento misoprostol para inducir el aborto. Es necesario analizar las prácticas de los vendedores de farmacias respecto a sus recomendaciones sobre el misoprostol en todas las regiones de México después de la legalización del aborto en el Distrito Federal.

Métodos: En términos generales, 192 farmacias en cuatro regiones de México fueron seleccionadas y visitadas por clientes simulados que representaban tres escenarios (una mujer joven, una mujer adulta y el compañero de una pareja). Se utilizó análisis bivariado y multivariado para explorar las asociaciones de las características de las farmacias, vendedores y clientes con el acceso al medicamento.

Resultados: En 558 encuentros con clientes simulados, un total del $78 \%$ de los vendedores proporcionó información sobre el misoprostol-18\% lo recomendó de manera espontánea y otro 60\% lo recomendó solamente después de que la o el cliente preguntó específicamente por el medicamento. El 15\% de los vendedores recomendó un régimen de dosificación del misoprostol que era potencialmente efectivo. Las farmacias ubicadas en la Ciudad de México y en la región Central tuvieron significativamente menor probabilidad que las de la región Norte de requerir una receta para vender misoprostol (razones de momios, 0.2 y 0.3 , respectivamente). Las farmacias independientes y aquellas situadas en zonas de bajos ingresos tuvieron significativa- mente mayor probabilidad de vender misoprostol por pieza (píldora) que las farmacias de cadena y aquellas ubicadas en zonas de medianos ingresos (3.2 y 2.7, respectivamente).

Conclusion: El acceso al misoprostol se ve influido por el nivel socioeconómico del vecindario, la ubicación de la farmacia y el tipo de farmacia. La frecuentemente inexacta e incompleta información que se proporciona a la clientela sobre el uso del misoprostol para inducir el aborto, sugiere la necesidad de mejorar la capacitación de los vendedores de farmacias sobre el aborto con medicamentos y de desarrollar las opciones para informar directamente a las mujeres sobre el uso de misoprostol.

\section{RÉSUMÉ}

Contexte: Le misoprostol était déjà utilisé par les femmes du Mexique à des fins abortives avant 2007, année de la légalisation de l'IVG du premier trimestre à la ville de Mexico. Il convient d'examiner les pratiques de recommandation du misoprostol dans les pharmacies des sous-régions du Mexique après la légalisation de l'IVG.

Méthodes: Dans l'ensemble, 192 pharmacies ont été sélectionnées aléatoirement dans quatre régions du Mexique et visitées par des clients simulés selon trois scénarios (une jeune femme, une femme adulte et un partenaire masculin). Les associations entre les caractéristiques de pharmacie, vendeur et client et l'accès au médicament ont été examinées par analyses bi-et multivariées.

Résultats: Sur 558 rencontres avec les clients simulés, 78\% des vendeurs ont fourni une information sur le misoprostol-18\% l'ont recommandé spontanément et $60 \%$ sur demande spécifique du ou de la cliente seulement. Quinze pour cent des vendeurs ont recommandé une posologie potentiellement efficace. Les pharmacies de la ville de Mexico et celles de la région centrale du pays se sont montrées significativement moins susceptibles que celles de la région du nord d'exiger une ordonnance pour la vente de misoprostol (rapports de probabilités, 0,2 et 0,3 , respectivement). Les pharmacies indépendantes et celles des milieux économiquement défavorisés se sont révélées significativement plus susceptibles de vendre le misoprostol au comprimé que celles faisant partie d'une chaîne ou celles des milieux moins défavorisés (3,2 et 2,7, respectivement).

Conclusions: L'accès au misoprostol dépend du niveau socioéconomique du quartier, de l'emplacement de la pharmacie et de son type. L'information souvent inexacte et incomplète donnée aux clients concernant l'usage du misoprostol à des fins abortives laisse entendre la nécessité d'améliorer la formation des vendeurs de pharmacie aux options d'avortement médicamenteux et de mettre au point des moyens d'informer directement les femmes sur l'usage du misoprostol.

\section{Acknowledgments}

This study was made possible by the generous support of an anonymous donor. The authors are grateful to the Buro de Investigación de Mercados and all fieldwork staff, as well as to Laura Carrillo and Abby Krumholz for their research and editorial support.

Author contact:dlara@ibisreproductivehealth.org 